European Research Studies, Volume XIII, Issue (1), 2010

\title{
Physical and Human Capital Complementarity and Worker Effort Level by Nutritional Level within Labor-Augmenting Solow Type Model
}

\author{
Erkan Erdil ${ }^{\mathrm{a}}$ and Kahraman Kalyoncu ${ }^{\mathrm{b}}$
}

\begin{abstract}
:
Whether the convergence occurs is one of the important issues in economic growth. Besides occurrence of convergence, another important issue in the theory of economic growth is whether the growth of per-capita income depends on the ratio of physical to human capital $(\mathrm{K} / \mathrm{H})$ where human capital is defined by the education and the worker effort level calculated by per capita dietary energy supply (DES). This study provides evidence for imbalance effects of $(K / H)$ on growth rate besides convergence issue in a sample of 36 countries. This dependence causes the change in size of convergence rate where with the conditions on $(\mathrm{K} / \mathrm{H})$ ratio, convergence rate increases.
\end{abstract}

Key words: economic growth; human capital; physical capita.

JEL classification: 04

\section{Introduction}

The physical to human capital ratio is designed in augmenting-labor Solow type model rather than level of them. It is believed that the growth of output depends on the physical to human capital ratio where human capital is not only measured by education but also by health or nutrition status. Therefore, human capital is defined in this study with individual education level and nutritional status. If there is an imbalance effect between physical and human capital, the imbalance effect that is a symmetric condition on the physical to human capital ratio will be significantly below or above its steady-state value. The asymmetric imbalance effect is demonstrated by an asymmetric U-shaped dependence or if the per capita output growth depends equally positively or equally negatively on the physical to human ratio (Duczynski, 2003). Barro and Sala-i-Martin (1995) and Mankiw et.al. (1992) roughly state evidence that growth depends positively on the physical to human capital ratio. Islam (1995) finds negative human capital coefficients. This negative sign of human capital a Department of Economics, Middle East Technical University Ankara Turkey, erdil@metu.edu.tr

b Department of Economics, Middle East Technical University Ankara Turkey, kkalyunc@yahoo.com 
coefficients is considered by us to be an indication for the relevance of physical to human capital ratio in growth study. Ramcharan (2004) and Lee (2007) draw attention to the complementarities between human capital and physical capital. The complementarities between human capital and physical capital are the typical of the production procedure since equipment needs eligible workers to manage them and eligible mechanics to fix them. Moreover, even modern agricultural production requires a well-informed agriculture workforce where workers who can comprehend instructions on a fertilizer bag, understand information contained in manual distributed by extension agents and understand the contents of a repair manual for agricultural equipment and up-to-the-minute services want people who can make simple calculations rapidly and precisely. If countries focus on physical capital while ignoring their human capital, they will soon become conscious that the returns to physical capital are worse than they need to be then they will have poorer output. Lee (2007) also exposes that introducing superior methods of production, new ways of doing things and introducing more compound and complicated products are easier said than done if buyers, workers and consumers have unsatisfactory training and education to enable them to understand the new technology.

In this paper, we intend to extend the existing verification by examining the dependence of the per capita output growth for 1990 and 2000 on the initial level of per capita GDP and physical to human capital ratio for 36 countries. We present the data in the following section. In section 3 , we describe the model and we present the results. The last section discusses the main findings.

\section{Data}

We have used data for 1990 and 2000 for 36 countries where 1980' per-capita GDP level data is picked up for starting initial income level. The physical capital to education*worker effort level data is calculated as electric power consumption $(\mathrm{kWh})$ to Education $(\mathrm{E})$ data times the worker effort index (e) $\left(\mathrm{EL} / \mathrm{E}^{*} \mathrm{e}\right)$. EL/E*e electric power consumption $(\mathrm{kWh})$ shown as (EL) stands for physical capital proxy and Education (E) data is the total educated people who took average Years of School from educational attainment of the aged 15. Per capita dietary energy supply (DES) is taken from $\mathrm{FAO}^{1}$ to calculate the worker effort level (e). Total population variables are taken from the World Development Indicators to calculate population growth rates. GDP per capita and total populations and EL/E*e electric power consumption $(\mathrm{kWh})$ are from World

\footnotetext{
${ }^{1}$ http://www.fao.org/News/1998/981204-e.htm
} 
Physical and Human Capital Complementarity and Worker Effort Level by 75 Nutritional Level within Labor-Augmenting Solow Type Model

Bank's World Development Indicators ${ }^{2}$. Education (E) data comes from the Barro- Lee data set. Change in physical capital to education data is calculated as change in EL/E*e electric power consumption $(\mathrm{kWh})$ to Education $(\mathrm{E})$ data and the worker effort index (e) $\left(\mathrm{EL} / \mathrm{E}^{*} \mathrm{e}\right)$.

\section{The Key Empirical Evidence in a Cross-Section Data}

Since we aim to use physical to human capital ratio as the complementary interaction in our augmenting Solow model, we should draw the graphics of the average-per-capita income growth and the EL/E*e. The dependence on the per-capita income growth on $\mathrm{K} / \mathrm{H}$ ratio in figure 1 is not $\mathrm{U}$ shaped. One-sector endogenous growth models anticipate a U-shaped dependence of production growth on the inverse ratio of physical to human capital (see Barro and Sala-i-Martin, 1995). Duczynski (2003) mentions that economic growth theory ambiguously implies the imbalance effect. This imbalance effect is described as the ratio of physical to human capital or human to physical capital. As we see from the figure 1, total and sub-samples shows no U-shaped. However, it is hard to conclude there is a positive relationship between average-per-capita income growth and EL/E*e except for high-income sub sample and whole sample.

The average of $\left(\mathrm{EL} / \mathrm{E}^{*} \mathrm{e}\right)$ is the 650066.1 and the standard deviation equals 617684.1. The average of average-per-capita income growth is 0.202358 and the standard deviation equals 0.1988373 . We have also report for the sub sample. For the high income level countries (according to World Bank 2002 classification where mid and low income level countries are reported in the same group), the average of average-per-capita income growth is 0.204 and the standard deviation equals 0.124 , the average of $\left(\mathrm{EL} / \mathrm{E}^{*} \mathrm{e}\right)$ is the 1081703 and the standard deviation equals 656372.1. For the low income level countries, the average of average-per-capita income growth is 0.20 and the standard deviation equals 0.25 , the average of $\left(\mathrm{EL} / \mathrm{E}^{*} \mathrm{e}\right)$ is the 284834.5 and the standard deviation equals 226639.3. Both of these statistics are higher in the high-income countries. The correlation of the average of $\left(\mathrm{EL} / \mathrm{E}^{*} \mathrm{e}\right)$ and average-per-capita income growth for the whole sample is $-0.0745(0.5341)$. It is $-0.2106(0.2394)$ for highincome level and it is $-0.0660(0.6899)$ for the low-income level. The significances levels are in the parenthesis.

\footnotetext{
${ }^{2}$ http://devdata.worldbank.org
} 


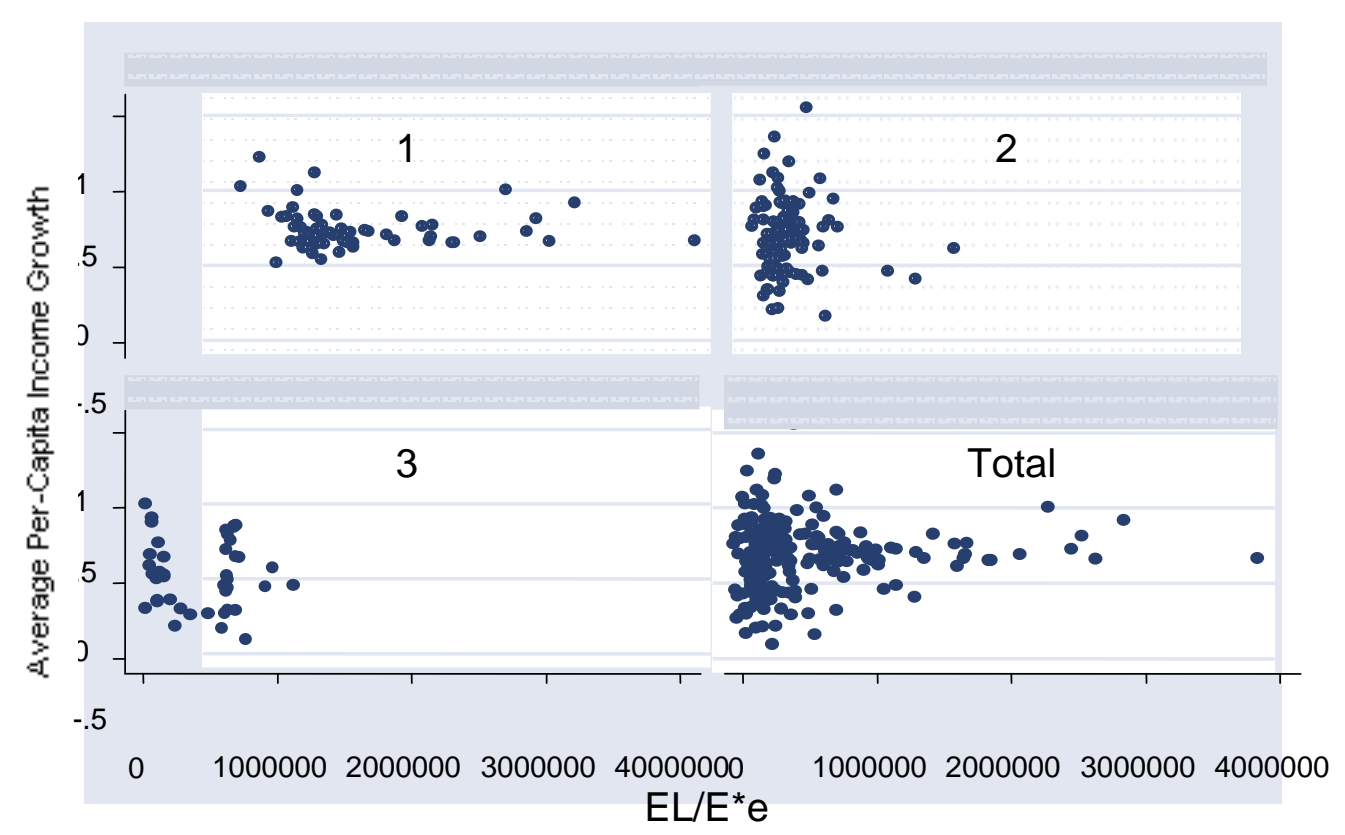

FIGURE 1: The dependence of average per-capita GDP growth on the ratio $\mathrm{EL} / \mathrm{E}^{*} \mathrm{e}$ :

1 stands for high-income level countries, 2 for mid-income level and 3 for low-income countries. Total stands for the whole sample. We have used same data for 1980, 1990 and 2000 for 69 countries for the simple statistics. The data set for the model estimation is calculated from this data.

\section{Convergence}

Whether the unfortunate countries grow faster than wealthy ones and how fast the average unfortunate countries becomes wealthy and how fast the average wealthy becomes unfortunate is the subject matter of convergence approach which is widely used in the literature (Barro and Sala-i-Martin, 1995; Levine and Renelt, 1992). Generally, the conditional convergence rate occurs at the rate of two percent per year (Kalyuncu, 1998). We set our model ratio of $(\mathrm{K} / \mathrm{H})$ within labor augmenting technology and the model is defined according to equation (1), (2) and (3), where $0<\alpha<1$.

$Y=\left(\frac{K}{H}\right)^{\alpha}(A e L)^{1-\alpha}$ 
where Y, e, L, K, H and A stands for output, the average level of worker effort (the effectiveness of labor) in a country, the number of workers, physical capital, human capital and the level of productivity, respectively. Where we define the human capital as $\mathrm{H}=\mathrm{E}^{*} \mathrm{e}$ (education*the worker effort level). $\alpha$ is the share of physical to human capital ratio in the production function. In terms of model dynamics, $A_{t}, L_{t}$ and $e_{t}$ are growing at a constant rate of $g$, of $n$ and $\gamma$, respectively.

$$
\frac{\stackrel{*}{A}}{A}=g \text { and } \frac{{ }^{*}}{L}=n \text { and } \frac{e^{*}}{e}=\gamma
$$

where "**, such as $\left(\frac{\mathrm{K}}{H}\right)_{t}$, denotes differentiations with respect to time Suppose a fixed fraction of output " $\mathrm{s}$ " is invested and the depreciation rate of capital ratio is $\delta$ then the dynamics of physical to human capital ratio accumulation is given by:

$$
\left(\frac{\mathrm{K}}{H}\right)_{t}=s Y_{t}-\delta\left(\frac{\mathrm{K}}{H}\right)_{t}
$$

We show $f(k)=\frac{Y}{e A L}$ and $k=\frac{K / H}{A e L}$

$$
\begin{aligned}
& * \\
& k=s f(k)-(n+g+\delta+\gamma) k \\
& \beta=(1-\alpha)(n+g+\delta+\gamma)
\end{aligned}
$$

and the steady state value of $\mathrm{k}$ is: $k^{*}=\left[\frac{s}{(n+g+\delta+\gamma)}\right]^{\left(\frac{1}{1-\alpha}\right)}$

In terms of panel specification; we should set absolute case in equation (6) and conditional case in equation (7).

$$
\begin{aligned}
& \frac{1}{T} \ln \left(\frac{y_{i t}}{y i_{t-T}}\right)=a-\left(\frac{1-e^{-\beta t}}{T}\right) \ln \left(y_{i t-T}\right) \\
& \frac{1}{T} \ln \left(\frac{y_{i t}}{y_{i t-T}}\right)=\left(\frac{1-e^{-\beta t}}{T}\right) \ln \left(y^{*}\right)-\left(\frac{1-e^{-\beta t}}{T}\right) \ln \left(y_{i t-T}\right)
\end{aligned}
$$

where $\mathrm{y}^{*},\left(y^{*}=\left[\frac{s}{(n+g+\delta+\gamma)}\right]^{\left(\frac{\alpha}{1-\alpha}\right)}\right)$, stands for steady state value of per capita income. Firstly, we assumed that the per capita income expressed by the worker effort level. Therefore, the change in the stock of $(\mathrm{K} / \mathrm{H})$ is a proxy with $(\mathrm{EL} / \mathrm{Ee}$ : electricity consumption to education*the worker effort level) and we can write steady state per capita income as 
$\ln \left(y^{*}\right)=\operatorname{Ln}\left(\frac{Y}{e L}\right)^{*}=\operatorname{Ln}(A)+\frac{\alpha}{1-\alpha} \operatorname{Ln}\left(k^{*}\right)$

$\operatorname{Ln}(\mathrm{A})$ is assumed to be constant, thus, we will show the conditional convergence regression as

$\frac{1}{T} \ln \left(\frac{y_{t}}{y_{t}-T}\right)=$ Constant $+\frac{\alpha}{1-\alpha}\left[\frac{1-e^{-\beta T}}{T}\right] \operatorname{Ln}(s)$

$-\frac{\alpha}{1-\alpha}\left[\frac{1-e^{-\beta T}}{T}\right] \operatorname{Ln}(n+g+\delta+\gamma)-\left[\frac{1-e^{-\beta T}}{T}\right] \ln \left(y_{0}\right)$

where s displays the changing in $(\mathrm{EL} / \mathrm{Ee}): s=\Delta\left[\frac{E L}{E e}\right]$.

$e^{i}=\left(4.34 * 10^{(-4)}\right) *\left(x_{C}^{i}\right)-\left(4.16^{*} 10^{(-8)}\right)\left(x_{C}^{i}\right)^{2}$

where $e_{i}$ is efficiency (endurance level) units of labor for worker $i$ and $x_{c}^{i}$ is the daily calorie intake (per-capita dietary energy supply) at the individual level. It is assumed that all workers are indistinguishable in a country, so "e" shows countries' effectiveness units of labor from a common worker and $\mathrm{x}_{\mathrm{c}}$ denotes DES value. Since some values of the change in $(\mathrm{EL} / \mathrm{Ee})$ are negative (where taking the log of the negative value is impossible), we have taken the standard deviation of each variable and added one (except dependent variable). Therefore, we are able to use all the observations.

TABLE 1: Convergence and Imbalance Effects (OLS)

\begin{tabular}{|l|r|r|}
\hline Dependent variable: GDP per-capita average growth rate \\
\hline $\log \left(\mathrm{y}_{\mathrm{t}-\mathrm{T}}\right)$ & -0.3 & -1.06 \\
\hline $\mathrm{Ln}(\mathrm{s})$ & -1.22 & $(-3.14)^{* *}$ \\
\hline & & 0.6 \\
\hline $\mathrm{Ln}(\mathrm{n}+\mathrm{g}+\delta+\gamma)$ & & $(1.79)$ \\
\hline & & -1.05 \\
\hline $\mathrm{Constant}$ & & $(-2.76)^{*}$ \\
\hline & 1.19 & 2.26 \\
\hline Observations & $(6.50)^{* *}$ & 4.68 \\
\hline $\mathrm{R}$-squared & 72 & 72 \\
\hline Convergence rate & 0.0207 & 0.1444 \\
\hline Absolute value of $\mathrm{t}$ statistics in parentheses * significant at 5\%; $* *$ significant at $1 \%$ \\
\hline
\end{tabular}


By using white test for heteroskedasticity, data for both regression demonstrates homoskedasticity (Prob $>$ chi2 $=0.0093$ (absolute) and 0.0974 (conditional)). In table I., we have observed insignificant absolute convergence and the convergence takes place around $11 \%$ per year from the year 1990 to 2000 . Even though the economic growth theory has unclear implication concerning the imbalance effect and no characteristic implication for growth model in which the production growth depends homogeneously and negatively on changing in $(\mathrm{K} / \mathrm{H})$ ratio, our empirical model recommends that there is significantly positive relationship between economic growth and changing in $(\mathrm{K} / \mathrm{H})$. The convergence rate enhances with the conditions where the rate is around $24 \%$ per year from the year 1990 to 2000 . The $\mathrm{R}^{2}$ of conditional model is at least 7 times higher than the absolute convergence estimation.

The model constraint is also emphasized as in the equation (11) and the results are shown in Table 2 . The model naturally impose this restriction that the coefficients on the $\operatorname{Ln}(\mathrm{s})$ and $\operatorname{Ln}(\mathrm{n}+\mathrm{g}+\delta+\gamma)$ sum to zero as shown: $\operatorname{Ln}(\mathrm{s})-$ $\operatorname{Ln}(\mathrm{n}+\mathrm{g}+\delta+\gamma)$.

$$
\begin{aligned}
& \frac{1}{T} \ln \left(\frac{y_{t}}{y_{t-T}}\right)=\text { Constant }+\frac{\alpha}{1-\alpha}\left[\frac{1-e^{-\beta T}}{T}\right]\langle\operatorname{Ln}(s)-\operatorname{Ln}(n+g+\delta+\gamma)\rangle \\
& -\left[\frac{1-e^{-\beta T}}{T}\right] \ln \left(y_{0}\right)
\end{aligned}
$$

TABLE 2: Restricted Convergence Regression and Imbalance Effects (OLS)

\begin{tabular}{|l|r|}
\hline Dependent variable: GDP per-capita average growth rate \\
\hline $\log \left(\mathrm{y}_{\mathrm{t}-\mathrm{T}}\right)$ & -0.96 \\
\hline $\mathrm{Ln}(\mathrm{s})-\mathrm{Ln}(\mathrm{n}+\mathrm{g}+\delta+\gamma)$ & $(-2.99)^{* *}$ \\
\hline & 0.79 \\
\hline Constant & $(2.98)^{* *}$ \\
\hline & 1.9 \\
\hline Observations & 6.47 \\
\hline R-squared & 72 \\
\hline Convergence rate & 0.1327 \\
\hline Alpha value & 0.23 \\
\hline Absolute value of $t$ statistics in parentheses * significant at 5\%; ** significant at $1 \%$ \\
\hline
\end{tabular}


The convergence occurs and the restriction is hold. However, the coefficient of changing in $(\mathrm{K} / \mathrm{H})$ is higher in the restricted model and the convergence rate is lower. Taken as a whole, our analysis of the evidence on convergence issue contrast stridently with the endogenous-growth advocates. Comparing our findings within the literature, the convergence rate is higher with changing in (EL/Ee) than the changing in level of physical capital and human capital proxies in production function. Since changing in $(\mathrm{EL} / \mathrm{Ee})$ causes an increase in convergence rate, the model may has significant policy implication. It could be answer why physical capital fails to move from lower rate of return to higher rate of return rich to poor because without human capital it can not operate.

Therefore, in order to move physical capital from lower rate of return to higher rate of return, at least for training to utilities of that physical capital there should be allocation of some minimum level of human capital. Even though marginal product of physical capital should be higher in low-saving countries, without human capital it would not get such high rate of return. 
Physical and Human Capital Complementarity and Worker Effort Level by 81 Nutritional Level within Labor-Augmenting Solow Type Model

\section{Conclusion}

We have suggested that the international differences in income percapita are best understood using an augmented Solow growth model where physical to human capita ratio is employed instead their level in production function. In our model, output is produced from physical to human capital ratio and labor, and that output is used for investment in physical to human capital ratio and consumption. The key object of the paper is to investigate how well physical to human capital ratio fits in the empirical growth study besides the convergence issue. Even though neither figure 1 nor correlation support the positive relationship between average per-capita income growth and EL/E*e, there is a significant positive relationship between the average per-capita income growth and changing in EL/E*e. This study provides evidence that the interaction between $(\mathrm{K} / \mathrm{H})$ and economic growth tends to be positive in the sample of 36 countries for the years 1990 and 2000. More generally, our result indicates that Solow model consistent with the international evidence even if we employ $(\mathrm{K} / \mathrm{H})$.

Therefore, our augmenting Solow model says that the differences in saving (changing in $\left(E L / E^{*} E\right)$ ) and population and endurance level growth should explain cross-country differences in per-capita income. The convergence rate is higher than $2 \%$ which is greater than general findings. The utilized data may be consistent with the two-sector models of endogenous growth with large adjustment expenses for shifting human capital and models of technological diffusion. Investigating the straight relationship between the physical to human capital ratio and the output growth seems to fit well, which provide only indirect confirmation for the imbalance effect.

\section{References:}

1. Barro, Robert and Sala-i-Martin, X. S (1995) "Economic Growth" McGraw-Hill, Inc.

2. Duczynski, P., (2003) "On the Empirics of the Imbalance Effect" International Journal of Business and Economics, 2003, Vol. 2, No. 2, 121-128.

3. Islam, N. (1995) "Growth Empirics: A Panel Data Approach" quarterly Journal Of Economics, 110, 4, 1127-70.

4. Kalyüncü, K. (1998) "A Survey Of Recent Empirical Studies of Growth" Master Thesis, Indiana University, Bloomington.

5. Lee, J-W., (2007) "Economic Growth and Human Development in the Republic of Korea", 1945-1992"

6. http://gd.tuwien.ac.at/soc/undp/oc24aa.htm.

7. Levine, R. and Renelt, D. (1992).A sensitivity analysis of cross-country growth regressions. American Economic Review, 82(4):942-963. 
8. Mankiw, N.G.; Romer. D; Weil D.N. (1992) "A Contribution to the Empirics of Economic Growth" Quarterly Journal of Economics, 107 (2), 407-437.

9. Ramcharan, R. (2004) "Higher or Basic Education? The Composition of Human Capital and Economic Development" IMF Staff Papers Vol. 51, No. 2, 2004 International Monetary Fund. 